\title{
EXPERIÊNCIAS DE MULHERES NEGRAS DA FAVELA DE HELIÓPOLIS (SP) COM A VIOLÊNCIA E SUAS ESTRATÉGIAS DE ENFRENTAMENTO
}

EXPERIENCES OF BLACK WOMEN FROM SHANTYTOWN OF HELIÓPOLIS IN SAO PAULO WITH VIOLENCE AND THEIR STRATEGIES OF RESISTANCE

\author{
Alessandro de Oliveira dos Santos* \\ Jackeline Aparecida Ferreira Romio** \\ Christen Anne Smith ${ }^{* * *}$ \\ Flávia de Paiva Alves da Silva ${ }^{* * *}$
}

\begin{abstract}
*Professor do Instituto de Psicologia da Universidade de São Paulo (USP).
**Pós-doutoranda do Instituto de Psicologia da Universidade de São Paulo (USP).

${ }^{\star * \star *}$ Professora do Instituto Tereza Lozano de Estudos Latino-americanos da Universidade do Texas-Austin, Estados Unidos.

${ }^{\star * \star *}$ Graduanda em Direito pela Universidade Nove de Julho (UNINOVE).
\end{abstract}




\section{RESUMO}

No Brasil a experiência das mulheres negras com a violência está associada ao racismo. Neste artigo, discutimos tal violência com base no relato de mulheres negras da favela de Heliópolis, na cidade de São Paulo (SP). Trata-se de estudo qualitativo descritivo que, por meio de nove entrevistas, coletou informações sobre as concepções de violência desse segmento e suas estratégias de enfrentamento. A experiência com a violência, seja física ou simbólica, perpassa as histórias das entrevistadas, desde sua autopercepção como mulheres até suas vivências familiares, escolares, conjugais e de trabalho como mulheres negras. Para enfrentar a violência, utilizam estratégias pessoais e coletivas que envolvem a busca de informações sobre seus direitos e o suporte social e religioso.

PALAVRAS-CHAVE: mulheres negras; violência; racismo; estratégias de enfrentamento.

\section{ABSTRACT}

In Brazil, the experience of black women with violence is associated with racism. We discuss this violence from the report of black women from the "favela" of Heliópolis, in São Paulo. This is a qualitative descriptive study based on nine interviews. Through these interviews it was possible to obtain information about violence conceptions and coping strategies. The experience of violence, whether physical or symbolic, runs through the stories of the interviewees, from their self-understanding as women to their experiences, family, school, marital and working like black women. In order to face violence they use personal and collective strategies that involve the search for information about their rights and social and religious support.

KEYWORDS: black women; violence; racism; coping strategies. 
No Brasil a violência que acomete as mulheres negras vem há muito tempo sendo denunciada. Dados demográficos começaram a ser divulgados no país a partir de I996, com a inclusão do quesito cor/raça nos bancos de dados das organizações públicas. O que possibilitou, por exemplo, a identificação de taxas elevadas de mortalidade por homicídio da população negra, especialmente nas periferias das grandes cidades.

Edição recente do Atlas da violência produzido pelo Instituto de Pesquisa Econômica Aplicada (IPEA, 20I7) constatou que, em 2015, para cada Ioo homicídios, 7I vítimas eram pessoas negras. Atualizações desse estudo sequencial mostram que $75 \%$ dos homicídios foram contra pessoas negras. A pesquisa chama atenção para o recorte de cor/raça nos óbitos por homicídio entre as mulheres:

Os dados indicam que além da taxa de mortalidade de mulheres negras ter aumentado, cresceu também a proporção de mulheres negras entre o total de mulheres vítimas de mortes por agressão, passando de 54,8\% em 2005 para 65,3\% em 20I5. Trocando em miúdos, 65,3\% das mulheres assassinadas no Brasil no último ano eram negras, na evidência de que a combinação entre desigualdade de gênero e racismo é extremamente perversa e configura variável fundamental para compreendermos a violência letal contra a mulher no país. (IPEA, 20I7, p. 37)

Segundo Romio (20I3), para além da violência letal expressa pelos casos de homicídio, há um conjunto de violências simbólicas vivenciadas por essas mulheres que permanece invisível e deriva diretamente do racismo. Ao analisar os dados sobre vitimização da mulher por agressão física, de acordo com raça/cor, da Pesquisa Nacional por Amostra de Domicílios (PNAD) de 2009, a autora identificou diferença no número de mulheres que procuram a polícia. O registro policial foi mais frequente quando as vítimas eram brancas que quando eram negras, além de uma maior resistência da polícia em registrar queixas de mulheres negras como o principal motivo que impediu a efetivação das queixas para estas.

A experiência das mulheres negras brasileiras com a violência está associada ao racismo, que se configura como uma ideologia, uma estrutura e um processo. O racismo é uma ideologia por ser um conjunto de ideias sobre a existência de uma organização hierárquica de grupos de pessoas reunidas por características fenotípicas, como cor da pele, traços faciais e textura de cabelos, bem como por traços culturais, linguísticos, religiosos (SANSONE, 2OI4). É uma estrutura porque afeta a realidade objetiva e sua dinâmica social, política e econômica (SILVÉRIO, 2002), atuando dia a dia no estabelecimento daqueles que serão beneficiados voluntária ou involuntariamente - ou prejudicados, conforme cor/raça, em relação ao exercício de direitos políticos, sociais e humanos. E é um processo porque se transforma histórica e contextualmente. 
Ao longo dos séculos o racismo tem ajudado a legitimar a manutenção de privilégios e desigualdades persistentes no país. Contudo é preciso chamar atenção para as peculiaridades do racismo brasileiro em contraposição à ocorrência desse fenômeno em outros países. No Brasil, a manifestação do racismo é sutil, escapando dos modelos clássicos de explicação do fenômeno oriundos de teorias europeias e norte-americanas. O brasileiro não se identifica com o modelo racista padrão expresso na figura dos nazistas e fascistas e de grupos como Klu Klux Klan ou, na atualidade, White Powers. Essas características reforçam a ideia de que não há racismo no Brasil e contribuem para o não reconhecimento desse fenômeno pelos cidadãos no seu cotidiano. De acordo com Sansone (2OI4), no racismo operante nos países de colonização portuguesa, o qual denomina de "versão católico-latina do racismo" (p. 404), a força está centrada "na combinação intensa de intimidade-proximidade e violência mais que no binômio segregação-discriminação" (p. 405), de maior prevalência nos países de colonização anglo-saxônica.

A manifestação social do racismo é a discriminação racial, ou seja, toda distinção negativa, exclusão ou restrição baseada em cor/raça e capaz de pôr em risco liberdades fundamentais e direitos em quaisquer esferas. A manifestação individual do racismo é o preconceito racial, ou seja, se refere a percepções, atitudes e juízos preconcebidos a respeito de pessoas ou grupos de determinada cor/raça e que não são facilmente modificáveis por apresentação de evidência contrária (SANTOS, 20I2).

O preconceito e a discriminação derivados do racismo são cruciais para compreendermos o acesso (ou não) aos direitos, pois funcionam como determinantes da violação de direitos. Ayres et al. (2012) observam que onde há maior negligência e/ou violação de direitos é possível encontrar maior vulnerabilidade ao adoecimento, à marginalização e também à violência.

Quando pensamos em violência, consideramos com mais frequência sua manifestação física. A violência física é aquela que prejudica materialmente o corpo do(a) outro(a). No entanto, para além da violência física, existem outras formas de violência que também têm efeitos devastadores. Um exemplo seria a violência simbólica que as mulheres negras experimentam em uma sociedade onde as pessoas manifestam preconceito racial em relação a elas e não reconhecem sua beleza e sua inteligência.

Galtung (1969) define violência como o que ocorre quando as realizações somáticas e mentais das pessoas estão abaixo de suas "realizações potenciais" (p. I68). Nesse sentido, a violência pode ser compreendida como aquilo que separa o potencial da vida de sua ação real. Ou seja, diz respeito àquilo que limita o potencial para uma vida plena, seja em termos físicos ou simbólicos. Desse modo, é possível afirmar que o preconceito racial é uma forma de violência simbólica. Tal violência afeta diretamente a população negra e, em especial, as 
mulheres, na medida em que ao lado da opressão de raça - produzida pelo racismo -, existe a opressão de gênero - fruto do patriarcado -, que produz e reproduz relações de subordinação entre mulheres e homens na sociedade brasileira.

Este artigo apresenta resultados de uma pesquisa maior, que compreendeu os anos de 2016 a 20I8, intitulada Mulheres negras e violência: a luta por justiça no Brasil e EUA, que descreve as experiências de mulheres negras universitárias e de baixa renda dos municípios de São Paulo, no Brasil; e de Austin, nos Estados Unidos. A pesquisa intentou compreender quais são as semelhanças e as diferenças nas experiências dessas mulheres com a violência nos dois países e o que as convergências e divergências dessas experiências podem dizer sobre a situação das mulheres negras nas Américas.

O presente artigo, de caráter ensaístico, apresenta os principais resultados obtidos no âmbito da pesquisa maior junto a um segmento de mulheres negras de baixa renda da favela de Heliópolis, no município de São Paulo. O artigo focaliza as concepções sobre violência desse segmento e suas estratégias de enfrentamento. Por "concepções" entende-se a maneira pessoal de enxergar, sentir ou compreender algo sobre determinado fenômeno, objeto ou situação (CASTELEIRO, 200I). Nesse sentido, investigar a concepção de mulheres negras acerca da violência significa refletir sobre suas opiniões e práticas a esse respeito.

Favela diz respeito a um aglomerado urbano formado por ao menos 50 domicílios em área carente de saneamento básico e aparelhamento de saúde, educação e lazer (e não pertence aos seus moradores). A favela de Heliópolis formou-se em I97I com o adensamento promovido pela Prefeitura de São Paulo das favelas de Vila Prudente e Vergueiro, que deslocou os moradores para alojamentos provisórios. Após instalação dos alojamentos novos moradores chegaram construindo barracos nas proximidades e grileiros começaram a vender lotes (DOMINGUES et al., 20I8).

Em 2006, devido a mobilizações dos moradores, Heliópolis recebeu status de bairro, com a regularização das moradias e o início do fornecimento de energia elétrica, água e saneamento básico e instalação de equipamentos de saúde, educação e assistência social. Ocupando uma área de I milhão de metros quadrados, o bairro apresenta moradias como barracos, casas de alvenaria e prédios. Sua populaçãoé formada basicamente por pessoas que migraram da região Nordeste e seus atuais descendentes. Dispõe de um número significativo de famílias que vivem da economia informal e são lideradas por mulheres. Atualmente reúne aproximadamente 200 mil moradores, 18 mil residências e cerca de 3 mil estabelecimentos comerciais (DOMINGUES et al., 2018).

De maneira semelhante a outros bairros levantados a partir de favelas no Brasil, Heliópolis caracteriza-se ainda pela precariedade de infraestrutura em termos de saneamento 
básico e equipamentos de saúde, educação e lazer e por casos de violência relacionados, sobretudo, com a criminalidade e a ação da polícia. Por conseguinte as mulheres negras moradoras de Heliópolis precisam lidar cotidianamente com a experiência da violência.

\section{Método}

Trata-se de estudo qualitativo, descritivo e exploratório, com base em nove entrevistas com mulheres negras de Heliópolis na faixa etária de 22 a 67 anos, sendo três jovens entre 22 e 26 anos, três adultas entre 35 e 42 anos e três senhoras entre 64 e 67 anos. As entrevistas foram concedidas voluntariamente e os convites foram feitos por meio de abordagem direta com agente local. As entrevistadas não guardam relação de amizade, parentesco, trabalho ou escolar entre si, sendo selecionadas com base em sua pertença étnica racial, ou seja, a cor de pele preta ou parda, cuja combinação está em conformidade com a designação de mulher negra do Instituto Brasileiro de Geografia e Estatística (IBGE).

As entrevistas foram realizadas ao longo de 20I7, mediante assinatura de Termo de Consentimento Livre e Esclarecido (TCLE) pelas participantes do estudo. Duraram em média 60 minutos e foram conduzidas por um roteiro composto por perguntas tais como: Qual a primeira vez que você se entendeu como mulher? Qual foi a primeira vez que você se entendeu como mulher negra? Como é ser uma mulher negra? O que vem à sua cabeça quando a gente fala a palavra violência? Você sente mais violência vinda dos homens ou das mulheres? Pode contar um episódio/situação ligado à violência que você tenha ouvido falar, testemunhado ou vivido? Como você enfrenta/lida com a violência?

Todas as mulheres entrevistadas eram maiores de 18 anos. Seus nomes não foram identificados, sendo substituídos por nomes fictícios neste artigo. O Quadro I a seguir contém informações acerca do perfil de cada uma delas.

\section{Quadro 1. Perfil das mulheres entrevistadas.}

\begin{tabular}{|c|c|c|c|c|c|}
\hline Nome & Idade & Escolaridade & Profissão & Filhos & Religião \\
\hline Sabrina & 22 & Ensino médio completo & Cabeleireira & - & Evangélica \\
\hline Joana & 23 & Ensino superior incompleto & Desempregada & - & Católica \\
\hline Maria & 26 & Ensino médio completo & Recepcionista & 1 & Católica \\
\hline Vera & 35 & Ensino médio completo & Professora & 3 & Espírita \\
\hline Letícia & 38 & Ensino médio completo & Doméstica & 5 & Espírita \\
\hline Ana & 42 & Pós-graduação incompleta & Professora & 1 & Evangélica \\
\hline Leila & 64 & Ensino fundamental completo & Autônoma & 6 & Espírita \\
\hline Vitória & 66 & Ensino fundamental incompleto & Doméstica & 2 & Evangélica \\
\hline Márcia & 67 & Ensino fundamental incompleto & Aposentada & 2 & Católica \\
\hline
\end{tabular}

Fonte: Elaboração própria (2018). 
As entrevistas foram gravadas em áudio e o material foi transcrito. Em seguida foi feita uma análise buscando os principais conteúdos que emergiram do processo. Posteriormente, os conteúdos foram agrupados nas categorias: ser mulher, ser mulher negra, violência e estratégias de enfrentamento da violência. A construção das categorias foi feita com base nas similaridades temáticas presentes nas falas das entrevistadas de modo a permitir agrupamentos e discussões mais homogêneas sobre os conteúdos que afloraram (CARLOMAGNO; ROCHA, 20I6). Ao final, foram selecionados excertos de falas das entrevistadas para exemplificar os conteúdos recorrentes em cada categoria.

As entrevistadas não foram remuneradas e não houve custos decorrentes de sua participação na entrevista. O presente estudo, como já mencionado, faz parte de uma pesquisa maior, submetida e aprovada junto ao Comitê de Ética de Pesquisa do Instituto de Psicologia da Universidade de São Paulo, com o Certificado de Apresentação de Apreciação Ética (CAAE) número 62602716.9.0000.556I.

\section{Resultados}

Por meio da análise de conteúdo das entrevistas foi possível obter informações junto as participantes acerca das concepções de ser mulher e mulher negra, e identificar experiências com a violência e suas estratégias de enfrentamento.

\section{Ser mulher}

Ao longo do ciclo de vida existem eventos que marcam o ingresso na vida adulta. Para as mulheres negras o primeiro casamento, o primeiro filho e o primeiro emprego foram marcantes para sua construção de gênero como mulheres. Ao responderem à pergunta "Qual a primeira vez que você se entendeu como mulher?", as entrevistadas destacaram com mais frequência o momento do matrimônio, como exemplificam os excertos das falas de Letícia, Joana, Márcia e Vitória:

[...] minha mãe era bastante rígida, então o primeiro namorado que tive eu casei e fui embora, fui morar com ele e depois caiu a ficha, falei [para mim mesma] que mesmo tendo I6 anos eu sou mulher.(Letícia, 38 anos)

Eu me entendi como mulher a partir do momento que casei. Eu meio que fui mais mulher [...] devido à responsabilidade, que quando você se casa é totalmente diferente. (Joana, 23 anos)

[...] eu acho que [me entendi pela primeira vez como mulher] quando eu casei né? Casei com 20 anos. (Márcia, 67 anos) 
[...] depois que eu me casei eu me entendi como mulher [...] depois que a gente fica com o marido vai compreendendo, eles ensinam nós [sic] a viver, como é e como não é [...]. (Vitória, 66 anos)

As entrevistadas Vera, Letícia e Ana destacaram a gravidez e a maternidade como momentos importantes em suas vidas para a percepção de ser mulher, como exemplificam excertos de suas falas:

Eu engravidei com I5 anos, tive meu filho com I6, aí que eu fui entender o que era ser mulher, passei da adolescência precocemente e me entendi como mulher. (Vera, 35 anos)

[...] engravidei da minha filha com I6 anos [...] aí que [eu] fui me entender assim como mulher [...]. (Letícia, 38 anos)

Eu acredito que se tornar mulher mesmo, assim, é a partir do momento que a gente se torna mãe, quando tive minha filha foi aí que eu me identifiquei como uma mulher. (Ana, 42 anos)

Já para as entrevistadas Maria, Sabrina e Vitória foi a entrada na adolescência, associada à menstruação e à primeira relação sexual, que lhes permitiu perceber-se mulher, mostrando outro perfil mais precoce de entendimento da condição de mulher, como exemplificam os excertos de suas falas a seguir:

Com a maturidade, quando eu comecei a me tornar adolescente. (Maria, 26 anos)

Eu acho que para todas [as garotas] é quando vem a primeira menstruação, aí você começa a ver toda a mudança no seu corpo e começa a se entender como mulher. (Sabrina, 22 anos)

É depois que a gente tem relação [sexual], né? Depois, né? Aí pertence à mulher, né? (Vitória, 66 anos)

Para a entrevistada Márcia (67 anos), por sua vez, foi somente com a conquista de um emprego formal que veio a percepção de ser mulher. Em suas palavras:

[...] fui me sentir mulher mesmo quando eu saí de casa para trabalhar no Estado, eu tinha um registro [funcional], porque até então trabalhava como doméstica, sem vínculo nenhum.

A informalidade do trabalho como doméstica era um impedimento para que Márcia pudesse se perceber como mulher, considerando o registro funcional o marcador da sua passagem a esse status. 
Independentemente da faixa etária, em geral, para as entrevistadas o momento de percepção como mulher apareceu associado ao início da vida conjugal, sexual e reprodutiva, aliada à gravidez e ao matrimônio, que ocorreu, quase sempre, durante a adolescência. Tais concepções reavivam de uma maneira ou de outra a realidade construída em torno de um contexto de dominação e subordinação com base em uma hierarquia de gêneros - na qual às mulheres é destinado o universo da casa e do cuidado da família; e aos homens, o universo da rua e do trabalho -, agregada a um ingresso neste mundo mais precoce para mulheres negras e mediada pela luta em busca do ingresso no mercado de trabalho.

\section{Ser mulher negra}

Ao responderem à pergunta "Qual foi a primeira vez que você se entendeu como mulher negra?", as entrevistadas destacaram com mais frequência as situações de preconceito vivenciadas na infância ao lado família e, sobretudo, na escola, expressas na perseguição devido à textura do cabelo e à cor de pele, como exemplificam as falas de Letícia, Sabrina, Vera e Ana:

[...] a partir do momento que você vai para escola você já se entende [como negra] porque os amiguinhos zoam sabe, tira sarro do cabelo da gente, da cor da gente. (Letícia, 38 anos)

[...] fui vendo que algumas amiguinhas se consideravam negras e vendo que era mais próxima a elas, mais a tonalidade da pele [...] meus primos me zoavam bastante porque eu tinha o cabelo afro, bem enroladinho, e eles vinham me chamar de cabelo duro. (Sabrina, 22 anos)

Eu sofria muito para ir para a escola porque o meu cabelo era black power e eu sofria muito com as brincadeiras [...]. (Vera, 35 anos)

O meu cabelo minha mãe cortava bem curtinho, na escola os meninos tiravam muito sarro de mim e eu odiava ir para a escola por causa disso, por que era motivo de chacota [...]. Teve um período mesmo da escola que eu não queria mais estudar. Eu falava para minha mãe que eu não queria estudar, sempre inventava uma desculpa para não ir para a escola. (Ana, 42 anos)

Os excertos de falas de Joana, Ana e Vitória, apresentados a seguir, indicam que a autocompreensão como mulher negra é um processo contínuo que envolve experiências de alteridade desde a família, de aceitação de si e criação de estratégias de superação do preconceito racial. 
[...] eu não sou da cor da minha mãe [de pele branca], então eu percebi que tenho uma cor diferente [...] para mim é algo aceitável, eu aceito. (Joana, 23 anos)

[...] não me aceitava como negra. Depois de estudos, formação, eu vi que não é vergonha, mas, acho que por tanto preconceito e racismo que a gente vê, a pessoa acaba se escondendo. (Ana, 42 anos)

[...] pensava que ia ficar velha e não casar por causa da minha cor, mas deu certo: me casei, estou vivendo com meu marido e ele não olha minha cor. Nós brigávamos e ele nunca me xingou de "nega" dentro de casa. (Vitória, 66 anos)

A percepção de ser mulher negra também envolveu situações de preconceito racial no trabalho, como apontam Maria e Márcia a seguir:

Eu sinto que é mais difícil [ser uma mulher negra], há muito preconceito, as pessoas veem você de forma diferente [no trabalho], acham que você não é capaz das mesmas coisas devido ao tom da sua pele. (Maria, 26 anos)

[...] é muito difícil ser mulher negra porque tem o preconceito no emprego, num lugar que você vai o pessoal já olha diferente, muito pelo preconceito. (Márcia, 67 anos)

A análise de conteúdo das entrevistas mostra que a percepção como mulher negra envolveu vivências na família, na escola e no trabalho de preconceito racial pelas entrevistadas, ou seja, é fruto de uma experiência de violência simbólica que se manifesta por meio de hostilidade e rejeição agressivas com base em noções de superioridade e inferioridade de raças fundamentadas pelo racismo.

\section{Violência}

Ao responderem à pergunta "O que vem à sua cabeça quando a gente fala a palavra violência?", as entrevistadas destacaram com mais frequência as agressões do tipo verbal e física sofridas por uma pessoa ou um grupo de pessoas, como exemplificam a seguir as falas de Joana, Maria, Ana e Márcia:

[...] isso [violência] é agredir alguém, tanto verbalmente como fisicamente. (Joana, 23 anos)

[...] a violência vem de diversas formas, não só agressões físicas, palavras ditas que você nunca mais vai esquecer... Violência verbal é bem maior que a física [...].(Maria, 26 anos) 
[...] tem a violência física, tem a violência verbal, que uma palavra dói mais do que um tapa, dependendo da palavra. (Ana, 42 anos)

Violência é espancamento, palavras fortes né? Isso para mim é uma violência. (Márcia, 67 anos)

Para a maioria das entrevistadas a violência é mais comum e recorrente entre os homens, expressando uma limitação em identificar formas de violência quando são contra a própria mulher, como exemplificam os excertos das falas de Joana, Letícia, Sabrina, Ana, Leila, Vitória e Márcia a seguir:

[...] antigamente os homens eram mais agressores, devido o [sic] machismo, que pelo fato de poder mandar na mulher e a mulher obedecer, [se] subordinar, se a mulher não obedecia, ela entrava no "cacete". (Joana, 23 anos)

[...] tem homens com a cabeça bem fechada [...] não dá espaço para as mulheres [...] os homens são mais machistas. (Letícia, 38 anos)

Acho que pela brutalidade deles [homens], eles são mais estourados, não tem paciência para nada, aí acabo vendo mais isso [a violência] em homens. (Sabrina, 22 anos)

Olha, é complicado porque, assim, a gente vê tanta notícia hoje em dia de violência do homem contra a mulher, né? [...] eu acredito que dos homens [violência] para as mulheres sim [...]. (Ana, 42 anos)

A violência mais vinda do homem. (Leila, 64 anos)

Vem mais dos homens [violência], né? [...] eu vejo aí violência dos homens na rua, né? Eu vejo. (Vitória, 66 anos)

[...] as mulheres, acho que fazem é revidar, né [a violência]? Porque os homens têm ciúmes, querem ter poder, né? Querem ser dono das mulheres. (Márcia, 67 anos)

Ao responderem à pergunta "Pode contar um episódio/situação ligado à violência que você tenha ouvido falar, testemunhado ou vivido?", algumas entrevistadas destacaram episódios de violência em suas famílias, como exemplificam os comentários de Sabrina, Joana e Ana:

[...] já vi meu tio batendo na minha tia.(Sabrina, 22 anos)

[...] já vi minha mãe toda com hematomas, com a testa roxa, e também já presenciei meu cunhado batendo na minha irmã [...].(Joana, 23 anos) 
[...] meu pai achou ruim porque ela [mãe] estava conversando com o vizinho e começou a bater nela, e aí nós começamos a chorar. Conforme ela entrou para casa a gente foi ficar pertinho dela para ele não bater nela, e mesmo assim ele batendo, e sobrou para a gente também. Eu lembro que tinha uma cerca de arame farpado, que meu pai dividia o quintal, a horta do quintal que a gente brincava, e tinha um buraquinho que dá para passar um cachorro pequeno ali, e minha mãe teve que passar por ali para poder se livrar dele. (Ana, 42 anos)

Também houve entrevistadas que destacaram episódios de violência que testemunharam na rua, como exemplificam a seguir os excertos das falas de Sabrina, Maria, Letícia e Vitória:

[...] uma vez eu vi um rapaz tacando um tanquinho de lavar roupas nas costas da mulher [...]. (Sabrina, 22 anos)

[...] você vê tanta violência com a mulher no transporte público, assédio. (Maria, 26 anos)

[...] dentro do metrô entrou uma senhorinha e os mais jovens não se levantaram, sendo que tem os bancos preferenciais, né? Aí uma mocinha foi tirar satisfação e teve um rapaz que não gostou, sabe? E saíram na "porrada". (Letícia, 38 anos)

Eu já vi já, na rua aí, o povo brigando, né? Mulher com marido, brigando. (Vitória, 66 anos)

As entrevistadas Joana e Ana, por sua vez, relataram que já sofreram violência física:

[...] já fui vítima. Meu marido já chegou a me agredir [...]. (Joana, 23 anos)

[...] eu sofri isso também na minha infância. Meu pai era muito agressivo. Ele bebia, batia na minha mãe e vinha para o nosso lado, também, bater na gente. (Ana, 42 anos)

A análise de conteúdo das entrevistas mostra que as entrevistadas convivem com a presença da violência física e verbal tanto nas suas relações familiares e conjugais, mas também na rua. É possível constatar que a hierarquia e a subordinação das mulheres nas relações de gênero aprofundam a experiência da violência, afetando diretamente a autoestima e o bem-estar das entrevistadas. Essas violências também se entrecruzam às violências raciais experimentadas por suas condições de mulheres negras. 


\section{Estratégias de enfrentamento da violência}

No tema das formas de enfrentar a violência as entrevistadas indicaram estratégias pessoais e coletivas. A entrevistada Maria (26 anos), por exemplo, nunca procurou ajuda para lidar com as experiências de violência que viveu. Segundo ela: "a gente se policia mais, tem mais cuidado com o que fala e para quem fala; começa a rever os atos", sendo essa sua principal estratégia para evitar novos episódios de violência em sua vida. Já a entrevistada Vera (35 anos) destacou como estratégia para enfrentar a violência o pertencimento a uma religião.

Eu superei [as lembranças] essas situações [de violência]. Já evolui bastante. A maioria da minha família é espírita, então a gente se acolhe numa religião que te [sic] trata bem, a gente se apega na religião mesmo.

A ausência de religião foi mencionada por Letícia como um aspecto disparador da violência no mundo atual.

[...] as pessoas que não têm uma religião, não têm Deus no coração, né? Não param para raciocinar, põem na mente e já levam à frente, né? Não raciocinam. (Letícia, 38 anos)

Para enfrentar a violência as entrevistadas também utilizam estratégias coletivas, como a participação na associação comunitária de Heliópolis e em grupos na internet, como exemplificam os excertos das falas de Ana e Letícia.

A entidade onde eu trabalho (UNAS) tem o grupo de mulheres; quando tem algum ato, algum evento, eu vou. (Ana, 42 anos)

Tenho uns grupos no Facebook de negros, e tudo que engloba esse negócio da raça. Tenho uns grupos assim, participo [...] esses dias teve um filho de uma mulher que estava no Facebook que não queria mais ir para a escola porque chamaram ele de cabelo duro, e aí nesses grupos ensina a gente a falar com os filhos da gente, lidar com as situações. (Letícia, 38 anos)

Segundo Sabrina, Joana, Vera e Letícia, a igualdade com os homens, uma justiça mais rigorosa e o conhecimento dos próprios direitos são aspectos fundamentais para diminuir a violência contra as mulheres, como mostram os excertos de suas falas a seguir:

[...] igualdade porque o machismo está muito grande [...] os homens estão se sentindo muito os bambambã e acaba [sic] descontando a revolta nas mulheres. Acho que deveria começar por igualdade e prender quem faz isso. E justiça mais severa no Brasil.(Sabrina, 22 anos) 
[...] a gente não pode abaixar a cabeça para os homens [...] tem que dar um basta nisso [...] hoje eu posso falar: "não toque em mim que você sabe a consequência". (Joana, 23 anos)

Se informar, procurar direitos, fazer boletim de ocorrência [...]. (Vera, 35 anos)

[...] tem que saber quais são seus direitos [...] se alguém falar alguma coisa para mim que passou dos limites eu tenho meus direitos e eu posso procurar meus direitos. (Letícia, 38 anos)

Já a entrevistada Ana (42 anos) destaca o empoderamento feminino como um aspecto importante para diminuir a violência contra as mulheres.

Eu acredito que empoderando essas mulheres, mostrando para elas que elas são capazes sim de poder viver a vida delas sem depender de um homem, sem depender dessa violência, sabe? Porque antes a mulher era muito submissa, hoje a gente vê que isso não acontece mais, que as mulheres estão aí, guerreiras, lutando, batalhando; trabalhadoras e independentes. Então eu acho que é isso, empoderando essas mulheres para que elas cresçam e se fortaleçam para mostrar que elas são capazes de vencer na vida.

Para a entrevistada Leila, por sua vez, seria importante um trabalho de prevenção à violência.

[...] a imprensa passa o ocorrido [casos de violência], então porque não fazer uma divulgação para a prevenção? [...] a gente percebe que é mais fácil você divulgar a violência concretizada do que evitar, ter uma propaganda para evitar esta violência. (Leila, 64 anos)

Apenas Letícia e Márcia mencionaram a Lei Maria da Penha, principal marco legal para combater a violência contra a mulher, sendo que a primeira fez críticas e a segunda destacou a importância da lei.

[...] não funciona porque é que nem eu vejo no jornal, foi preso pela Lei Maria da Penha, aí tem uma liminar que o homem tem que ficar cem metros longe da mulher, mas a mulher não tem nenhuma proteção que o homem vai chegar perto dela, por isso que muitas tá [sic] perdendo sua vida, por isso acho que a Lei Maria da Penha deveria ser mais rígida.(Letícia, 38 anos)

Ah, eu acho boa [a lei], se manter, respeitar mesmo. A lei é boa, só as mulheres mesmo que fazem por onde não vá a frente, porque vai dar uma queixa e na mesma hora volta para o marido, vai retirar a queixa. Acho que é isso. (Márcia, 67 anos) 
Enfrentar a violência envolve adaptação a situações estressantes e estratégias para lidar com conflitos. A cautela, fruto da insegurança, além da busca de informações e suporte social e religioso foram as principais estratégias de enfrentamento mencionadas pelas entrevistadas.

\section{Discussão}

A análise de conteúdo das entrevistas com mulheres negras de diferentes faixas etárias de Heliópolis mostrou que para a maioria delas ainda existe um lugar demarcado para a mulher na sociedade brasileira que se relaciona, sobretudo, com a maternidade e a vida conjugal e doméstica. A tomada de consciência como mulher negra ocorre, em geral, por meio da violência simbólica do preconceito racial derivado do racismo, pois ser uma mulher negra implica ter de lidar com esse fenômeno e o desafio de construir uma autoimagem e uma identidade positivas.

Chamaram a atenção algumas falas das entrevistadas que apontam para uma tendência ao silêncio e à autorresponsabilização pela superação da violência sofrida. Também se notou um desapontamento com o sistema de justiça, sobretudo pela amenidade com a qual os perpetradores da violência, em geral os homens, são responsabilizados, bem como pela pouca proteção conferida às mulheres. Tais falas indicam que a opressão de gênero, fruto do patriarcado, que produz relações de subordinação entre mulheres e homens, associada ao racismo, engendra culpabilidade e vulnerabilidade entre as mulheres negras frequentemente relacionadas ao fato de não ter amparo do Estado para sair dessa situação.

A experiência com a violência, seja física ou simbólica, perpassa as histórias das entrevistadas, desde sua percepção como mulheres até suas vivências familiares, escolares, conjugais e de trabalho, operando como impedimentos para sua realização, pois geraram situações desfavoráveis que as limitou e desmotivou.

Para romper com a violência é necessário afastar os sentimentos de subordinação e culpa propícios à manutenção e à persistência dos abusos testemunhados ou sofridos. E isso tem sido perseguido pelas entrevistadas por meio de estratégias pessoais - como a busca de informação sobre seus direitos - e coletivas - como a participação na associação comunitária de Heliópolis e o pertencimento a uma religião, que se configuram como espaços de sociabilidade e rede de apoio. Trata-se de estratégias que contribuem para que essas mulheres possam romper com a condição de passivas e assujeitadas, e que podem estimular valores como coletividade, resistência e autodeterminação, sendo fundamentais para estruturação de identidades autoafirmadas (APARECIDA SANTOS, 2015).

Concordamos com Silva (1998) sobre as fontes mais genuínas de conhecimento a respeito das mulheres negras serem elas mesmas, e defendemos a realização de mais estudos que levem em consideração seus pontos de vista. Uma limitação do presente estudo foi o fato 
de o grupo investigado não compor uma amostra probabilística stricto sensu de mulheres negras de Heliópolis, mas apenas uma fotografia, ainda que parcial, dessa população, em uma tentativa de expressar sua riqueza em termos de faixa etária, escolaridade, ocupação e religião. Nesse sentido, os resultados descritos devem ser tomados mais como elementos capazes de subsidiar a compreensão acerca de algumas concepções sobre ser mulher negra e sobre violência entre as entrevistadas do que propriamente como afirmações finais sobre como as mulheres negras de Heliópolis concebem e lidam com a violência.

Indicadores de renda, escolaridade, habitação e condições de saúde, no Brasil, são sempre menores e/ou piores entre os negros. Negras e negros entram mais cedo e saem mais tarde do mercado de trabalho; têm, proporcionalmente, jornadas de trabalho mais longas se comparadas às dos brancos; ocupam as funções de menor qualificação profissional; desenvolvem as tarefas mais insalubres; e vivenciam situações de maior precariedade no trabalho(HERINGER, 2002).

Para que mudanças efetivas sejam alcançadas é necessária a intervenção efetiva e perene dos organismos do Estado na área da educação, da cultura e da saúde, visando à equidade de gênero e raça, e a promoção da saúde física e mental das mulheres negras. Como defende Carneiro (2003), impõe-se para as mulheres negras sua afirmação como um novo sujeito político, resultante de uma identidade específica, na qual se articulam lutas contra opressões de gênero e raça e que colocam novos desafios para efetivação da igualdade na sociedade brasileira.

\section{Referências}

APARECIDA SANTOS, G. Racismo institucional: uma análise a partir da perspectiva dos estudos pós-coloniais e da ética. Ensaios Filosóficos, n. 6, p. I45-165, 2015.

AYRES, J. R. C. M. et al. Conceitos e práticas de prevenção: da história natural da doença ao quadro da vulnerabilidade e direitos humanos. In: PAIVA, V.; AYRES, J. R.; BUCHALLA, C. M. (Orgs.). Vulnerabilidade e direitos humanos: prevenção e promoção da saúde - livro I, da doença à cidadania. Curitiba: Juruá, 2012.p. 7 I-94.

CARLOMAGNO, M. C.; ROCHA, L. C. Como criar e classificar categorias para fazer análise de conteúdo: uma questão metodológica. Revista Eletrônica de Ciência Política, v. 7, n. I, p. I73-I88, 2016.

CARNEIRO, S. Mulheres em movimento. Estudos Avançados, v. I7, n. 49, p. II7-I33, 2003.

CASTELEIRO, J. M. Dicionário da Língua Portuguesa Contemporânea. Lisboa: Academia das Ciências de Lisboa; Editorial Verbo, 200 .

DOMINGUES, A. R. et al. As principais violações de direitos de crianças e adolescentes em Heliópolis, São Paulo, Brasil. Revista Desidades, v. 19, n. 6, p. 36-47, 2018. 
FERREIRA, R. S. Classes populares, poder e punição. 2002. 168 f. Dissertação (Mestrado em Sociologia) - Faculdade de Filosofia, Letras e Ciências Humanas, Universidade de São Paulo, São Paulo, 2002.

GALTUNG, J. Violence, peace, and peace research. Journal of Peace Research, v. 6, n. 3, p. I67I9I, I969.

HERINGER, R. Desigualdades raciais no Brasil: síntese de indicadores e desafios no campo das políticas públicas. Cadernos de Saúde Pública, Rio de Janeiro, n. I8, p. 57-65, 2002.

IPEA - Instituto de Pesquisa Econômica Aplicada. Atlas da violência 20I7. Rio de Janeiro, 2017. $123 \mathrm{p}$.

ROMIO, J. A. F. A vitimização de mulheres por agressão física segundo raça/cor no Brasil. In: IPEA - Instituto de Pesquisa Econômica Aplicada. Retrato das desigualdades de gênero e raça. Brasília: SPM; IPEA; UNIFEM, 20I3. 39 p.

SANSONE, L. Raça. In: SANSONE, L.; FURTADO, C. A. (Orgs.). Dicionário crítico das ciências sociais dos países de fala oficial portuguesa. Salvador: EDUFBA, 2OI4. p. 393-4II.

SANTOS, A. O. Superar o racismo e promover a saúde da população negra: desafios para o trabalho de prevenção ao HIV/Aids no Brasil. In: PAIVA, V.; AYRES, J. R.; BUCHALLA, C. M. (Orgs.). Vulnerabilidade e direitos humanos: prevenção e promoção da saúde - livro I, da doença à cidadania. Curitiba: Juruá, 2012. p. I45-163.

SILVA, P. B. G. Chegou a hora de darmos à luz a nós mesmas: situando-nos enquanto mulheres e negras. Caderno CEDES, v. 19, n. 45, p. 7-23, 1998.

SILVÉRIO, V. R. Ação afirmativa e o combate ao racismo institucional no Brasil. Cadernos de Pesquisa, n. I17, p. 219-246, nov. 2002. 